\title{
Bragg reflectors fabricated from multilayered porous silicon
}

\section{Refletores de Bragg fabricados a partir de multicamadas de silício poroso}

Luiz Angelo Berni ${ }^{1 *}$, Ellen Christine de Souza Galvão ${ }^{1}$

\section{ABSTRACT}

Properties of porous silicon obtained by electrochemical etching were studied using different current densities and hydrofluoric acid solutions in order to obtain a periodic structure of thin layers to produce Bragg reflectors in the visible region of the spectrum.

Keywords: Bragg reflectors, Porous silicon, Refraction index.

\section{RESUMO}

Propriedades do silício poroso obtido por ataque eletroquímico foram estudadas usando diferentes densidades de corrente e soluções de ácido fluorídrico para obter uma estrutura periódica de camadas com o objetivo de produzir espelhos de Bragg na região visível do espectro.

Palavras-chave: Espelho de Bragg, Silício Poroso, Índice de refração. 


\section{INTRODUCTION}

Since its discovery in the 1950s, Porous Silicon (PSi) has been studied in several applications such as microelectronics, optoelectronics, chemical and biological sensors, batteries, solar cells and biomedical devices ${ }^{1-6}$. With the improvement of techniques for characterization, mainly non-destructive and of fast execution, the possibilities of study and development of different types of devices have greatly increased. One of these techniques, known as spectroscopy liquid infiltration method (SLIM), was used in this work in conjunction with high-resolution scanning electron microscopy, providing the obtainment of several overlapping layers of porous silicon as well as the control of its thickness and porosity ${ }^{7}$.

Bragg reflectors are based on light interference from different layers. They are formed by the superposition of multiple layers with alternating refractive index. By the choice of the thickness and the refractive index of each layer it is possible to produce a high quality reflector in the photonic stopband. The optical thickness of each layer must be $1 / 4$ of the desired wavelength, as shown in Eq. 1, where $\lambda$ is the wavelength of the mirror, $n$ is the refractive index and $L$ is the thickness of the layer. And the optical thickness $(n L)$ of layers must be kept constant ${ }^{8}$.

$$
\lambda=4 n L
$$

There are several methods for obtaining porous silicon, but the conventional method for PSi formation is by electrochemical etching. In this case, the composition of the electrolyte and its concentration, applied current, anodizing time, temperature, type of dopants and dopant density of the silicon substrate are some factors that influence the morphology of PSi as pore size, thickness and the type of porous structure. In this work, PSi was obtained by electrochemical etching from a p-type crystalline silicon wafer $(100)$ of low resistivity $(0.01-0.02 \Omega . c m)$ in hydrofluoric acid (HF) solution.

The choice of a substrate with these characteristics is due to previous work that resulted in very homogeneous and reproducible PSi layers ${ }^{9}$. Since in the electrochemical etching of the porous silicon the current flows preferentially toward the deepest pores it is possible to produce dozens layers of different refractive index by modulating the current density during the etching. Scanning electron microscopy images were used to analyze the morphology in the PSi samples and to estimate the pore diameter and pore layer thickness. Using this data and SLIM, it was possible do measure the refractive index of each layer.

\section{FABRICATION SET UP}

The PSi samples were produced in a two-electrode cell with capacity of $6 \mathrm{ml}$ of solution (Fig. 1). The working electrode was the silicon sample with a diameter of $7 \mathrm{~mm}$, and the counter electrode a spiral platinum wire. The etching time ranged between $1 \mathrm{~min}$ and $20 \mathrm{~min}$, and the current density between $10 \mathrm{~mA} / \mathrm{cm}^{2}$ and $500 \mathrm{~mA} / \mathrm{cm}^{2}$. The $\mathrm{HF}(48 \%)$ acid was diluted in ethanol (99.5\%) in two different proportions, 1:1 and 3:1. All samples were produced at room temperature, $\sim 25^{\circ} \mathrm{C}$. Before PSi fabrication the chip was cleaned in the cell removing a sacrificial layer, which leaves the exposed surface of the substrate free of any organic material, oxidation or minor surface imperfections acquired with the handling, and is suitable for forming the desired pore patterns. This sacrificial layer was etched by HF solution under $200 \mathrm{~mA} / \mathrm{cm}^{2}$ during $30 \mathrm{~s}$ and then removed by a $1 \mathrm{M}$ aqueous $\mathrm{NaOH}$ solution approximately during $5 \mathrm{~min}$.

To obtain a single PSi layer the potentiostat is adjusted to apply the chosen current for the time required to obtain the desired thickness. In the case of mirrors, the potentiostat applies alternately the two chosen currents, therefore forming the layers with previously calculated refractive indices and thicknesses.

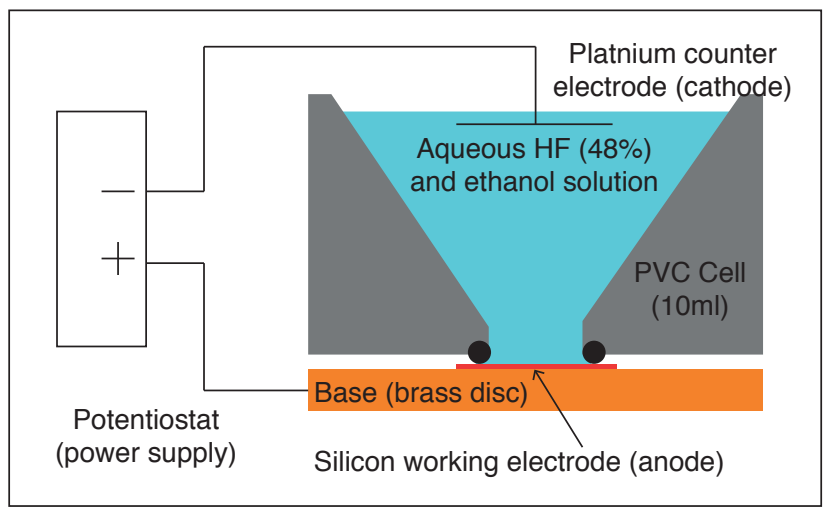

Figure 1: Two-electrode cell.

\section{RESULTS}

Initially, it was studied the relationship of porosity, refractive index and thickness as a function of the applied current density and the concentration of the HF solution during the PSi fabrication. For this, scanning electron microscopy (Tescan, model Mira 3) images were used to analyze the morphology in the PSi samples, as well as to estimate their thickness. Using SLIM, which measures the reflectance of PSi layer in the air and also immersed in some known liquid, it is possible from the analyses of the reflectance spectral patterns to estimate the thickness, refraction index and the porosity. For more details about SLIM, the set up used in this work and the approximation model used in calculations can be seen in Paes et al. ${ }^{7}$. Once fixed some parameters of the whole process, such as type, resistivity and dimensions of the silicon substrate, electrolytic solution and anodizing time, the porosity of the PSi layer can be controlled by the 
current density applied during the etching for each HF concentration. The porosity of the layer defines the refractive index that lies between the index of bulk silicon and air. And the thickness of the PSi layer is controlled by the etching time.

Figures 2 and 3 show the relationship between the refractive index and the thickness of PSi layer, respectively. These results were obtained by the spectroscopy liquid infiltration method. The refractive index calculated by SLIM is an average value obtained from the measured reflectance spectral signals between 600 and $900 \mathrm{~nm}^{7}$. It can be seen that using the HF $3: 1$ solution the refractive index of the layer is higher than using HF 1:1 solution for any applied current density, and the refractive index decreases with increasing current density. Furthermore, the thickness of PSi layer does not depend on the concentration of the solution (Fig. 3).

Figure 4 shows that the porosity of the PSi layer increases with current density, as expected. The thickness values of porous layers obtained with SLIM were compared with highresolution scanning electron microscopy showing great agreement, as can be seen in Fig. 5 .

To fabricate the first Bragg reflectors, were chosen wavelengths between 400 and $800 \mathrm{~nm}$. From curve of HF

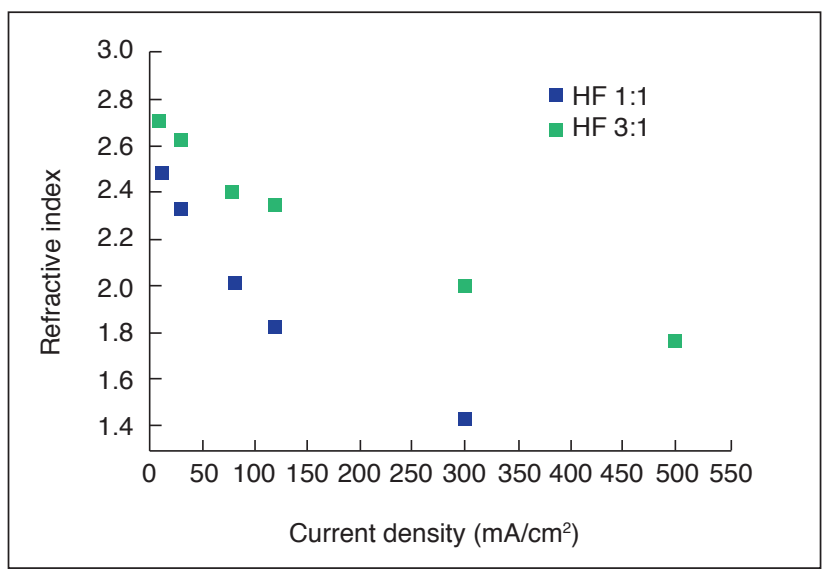

Figure 2: Average refractive index as a function of current density for two HF concentrations.

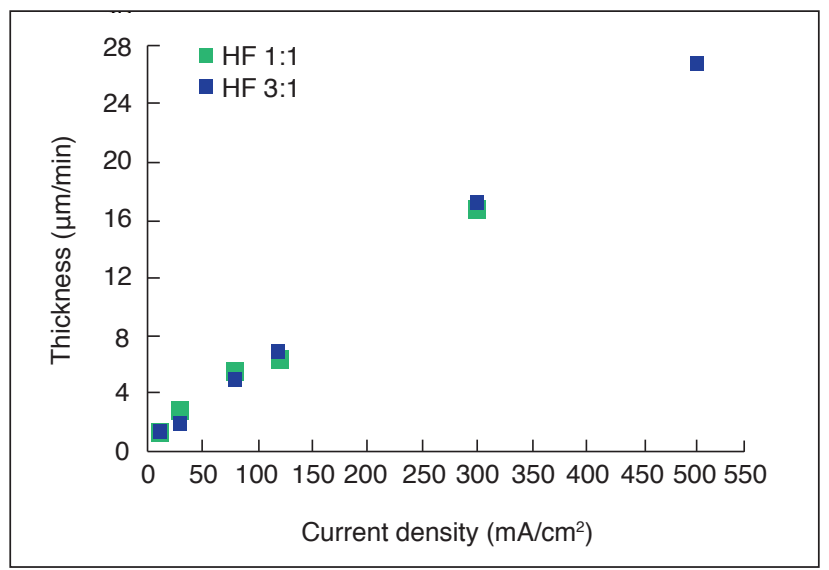

Figure 3:Thickness of PSi layer normalized by the etching time.
1:1 in Fig. 2, were chosen the refractive indices of 2.3 and 1.9 to form each layer. The refractive indices of each layer must be different and the larger the difference, the greater the reflected signal. For these values, were used current densities of 125 and $50 \mathrm{~mA} / \mathrm{cm}^{2}$, respectively. From Eq. 1, it was calculated the optical thickness of each layer, and using the graphic of Fig. 3 were determined the time of attack to form each layer.

Figure 6 shows details of PSi structures and side view of a Bragg mirror obtained with 30 layers (each layer corresponds to a pair of different refractive index). In the figure, it is possible to verify the dark and light regions that represent the high and low porosity layers of the Bragg mirror, respectively.

Figure 7 shows the reflectance of five PSi mirrors and it is possible to notice that the position of the peaks is shifted. That should be explained by the use of average values of refractive indices in the calculations, variations of the parameters during manufacturing as resistivity of the wafer, temperature, density current and HF concentration. As an example, Figs. $7 \mathrm{~b}, 7 \mathrm{c}$ and $7 \mathrm{~d}$ show three mirrors illuminated with white light.

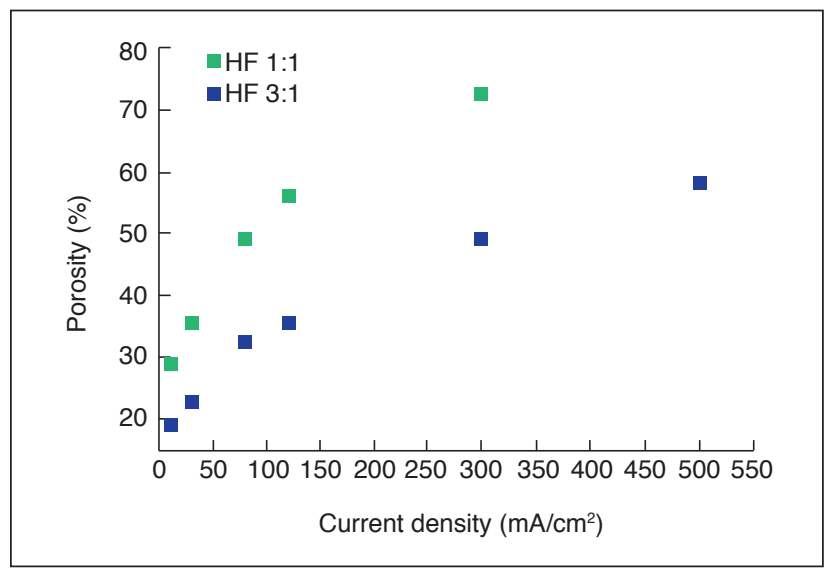

Figure 4: Porosity as a function of current density for two HF concentrations.

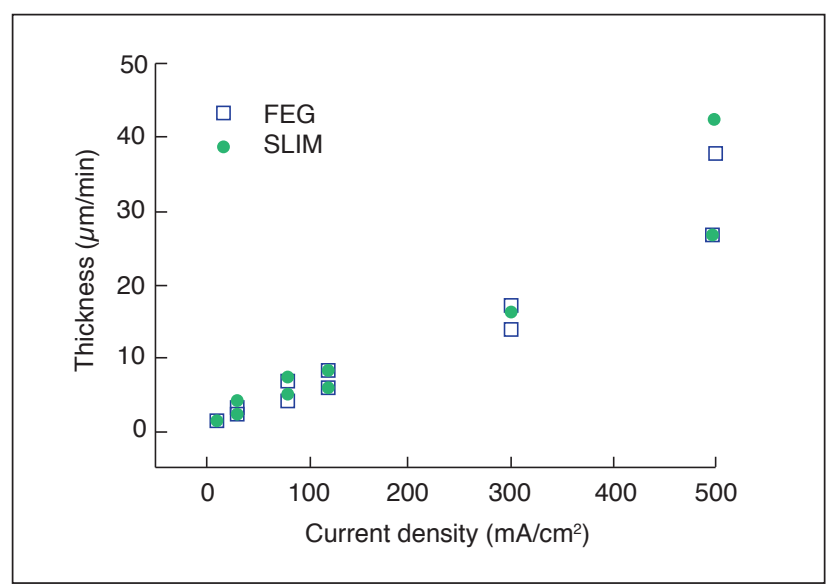

Figure 5: Thickness normalized by etching time, measured by highresolution scanning electron microscopy (FEG) and spectroscopy liquid infiltration method (SLIM). 
A

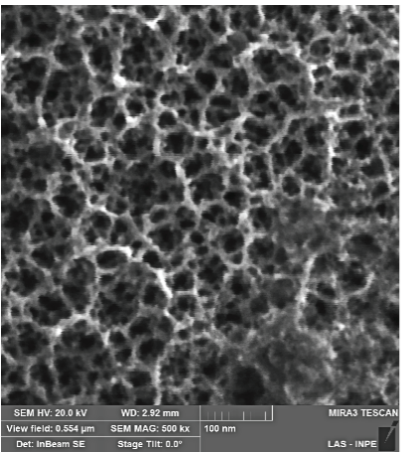

B

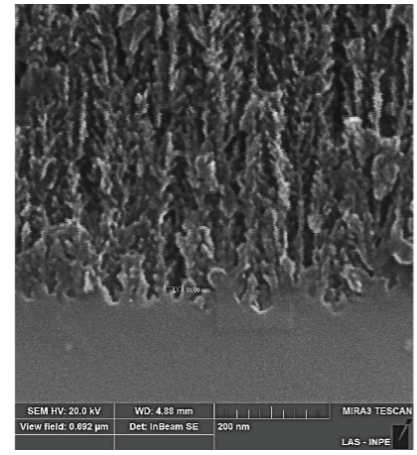

C

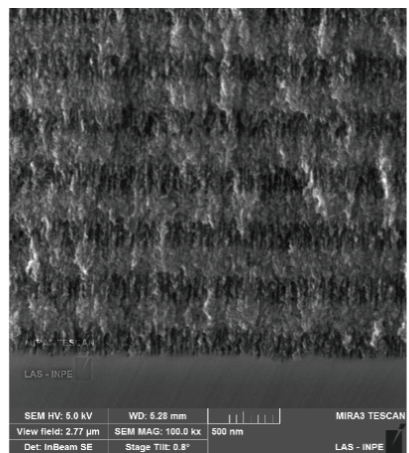

Figure 6: Top view from high-resolution scanning electron microscopy with magnification of (A) $500 \mathrm{~K}$; (B) side view of a single PSi layer with magnification of $300 \mathrm{~K}$; and $(\mathrm{C})$ layers details of a Bragg mirror with magnification of $100 \mathrm{~K}$.

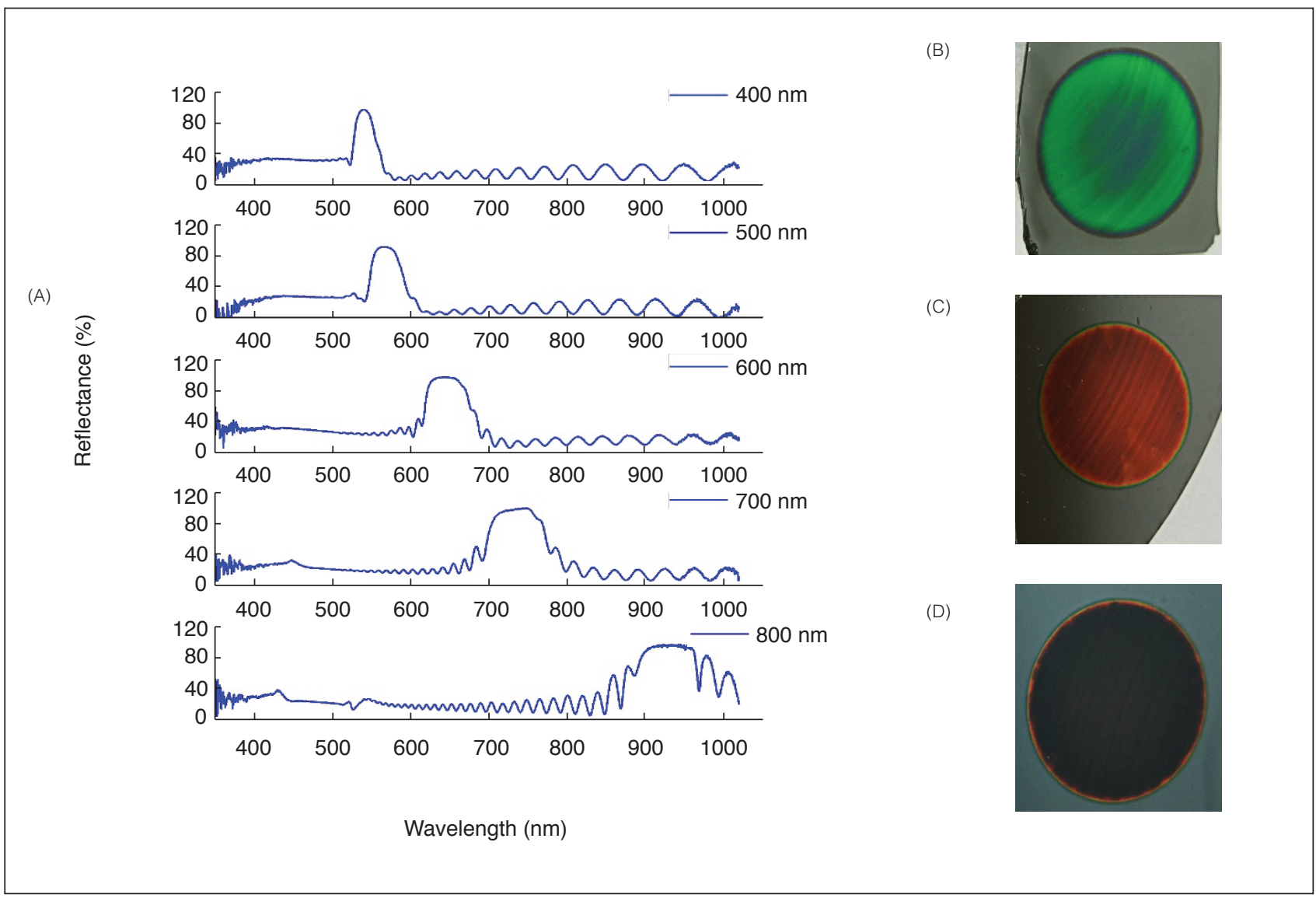

Figure 7: (A) Reflectance of PSi Bragg mirrors for 400, 500, 600, 700 and $800 \mathrm{~nm}$; (B) Mirrors manufactured for $500 \mathrm{~nm}$; (C) $600 \mathrm{~nm}$; (D) $700 \mathrm{~nm}$ illuminated with white light.

\section{CONCLUSIONS}

A setup for fabrication and analysis of porous silicon was installed in the laboratory providing systematic analysis of samples and PSi structures that can be used in the development of various types of devices. The process to obtain PSi by electrochemical attack of monocrystalline silicon was employed to fabricate specific structures with high homogeneity and reproducibility. Characterization techniques as high-resolution scanning electron microscopy and the Spectroscopy Liquid Infiltration Method were implemented for analysis of important parameters to obtain periodic structures of thin layers of PSi for the Bragg mirrors manufacture.

P-type silicon (100), (0.01 - 0.02) $\Omega . \mathrm{cm}$ and two solutions with HF (48\%) acid diluted in ethanol (99.5\%) in two different proportions, 1:1 and 3:1, were used. The results showed a very similar evolution, for both solutions, of the porosity, thickness and refractive index values for the PSi layers formed with the variation of the anodization conditions, although the 1:1 solution 
showed higher porosity values with the current density increase. For practical reasons we have chosen the 1:1 solution for the manufacture of some mirrors. As shown in the images of highresolution scanning electron microscopy, Bragg mirrors with 30 layers of PSi presented a fairly uniform structure. Measures of reflectance showed results very close to expectations showing a small shift in the peak reflectance that should be due to average values of refractive indices used in calculations, variations of the parameters as resistivity of the wafer, temperature and HF concentration during manufacture. In the future, we intend to analyze the effect of the amount of layers in the reflection band of the mirrors as a function of wavelength, study the degradation of the mirror due to oxidation, and produce more complicated structures as Fabry-Perot interference filters.

\section{ACKNOWLEDGMENTS}

The author Ellen Christine de Souza Galvão is grateful to $\mathrm{CNPq}$ for the fellowship.

\section{REFERENCES}

1. Lazarouk S, Jaguiro P, Katsouba S, Masini G, La Monica S, Maiello G. Ferrari A. Stable electroluminescence from reverse biased n-type porous silicon-aluminum Schottky junction device. Applied physics letters. 1996; 68(15):2108-2110. Available from: https://doi.org/10.1063/1.115892
2. Foucaran A, Pascal-Delannoy F, Giani A, Sackda A, Combette P. Boyer A. Porous silicon layers used for gas sensor applications. Thin Solid Films. 1997;297(1-2):317-320. Available from: https:// doi.org/10.1016/S0040-6090(96)09437-0

3. Li X, Gu M, Hu S, Kennard R, Yan P, Chen X, Wang C, Sailor MJ, Zhang J-G, Liu J. Mesoporous silicon sponge as an antipulverization structure for high-performance lithium-ion battery anodes. Nature communications. 2014;5:4105. Available from: https://doi.org/10.1038/ncomms5105

4. Ivanov II, Skryshevsky VA, Nychyporuk T, Lemiti M, Makarov AV, Klyui NI, Tretyak OV. Porous silicon Bragg mirrors on single-and multi-crystalline silicon for solar cells. Renewable Energy. 2013;55:79-84. Available from: https://doi.org/10.1016/j. renene.2012.12.031

5. Livney YD, Assaraf YG. Rationally designed nanovehicles to overcome cancer chemoresistance. Advanced drug delivery reviews. 2013;65(13-14):1716-1730. Available from: https://doi. org/10.1016/j.addr.2013.08.006

6. Sailor MJ. Porous silicon in practice: preparation, characterization and applications. Hoboken: John Wiley \& Sons; 2012

7. Paes TF, Beloto AF, Galvão ECS, Berni LA. Simple method for measuring the porosity, thickness and refractive index of porous silicon, based on the Fabry-Pérot interference spectrum. Rev. Bras. Apl. Vac. 2016;35(3):117-122. Available from: https://doi. org/10.17563/rbav.v35i3.1044

8. Hecht E. Optics. 4th ed. Boston: Addison-Wesley; 2002

9. Paes T. F. Silício poroso: estudo de estruturas e fotoluminescência para possíveis aplicações em sensores [Tese de Doutorado]. São José dos Campos: Instituto Nacional de Pesquisas Espaciais; 2016. 